\title{
Tocilizumab en artritis psoriásica ante la falla a los bloqueantes del factor de necrosis tumoral alfa: experiencia en dos casos
}

\author{
R. García Salinas, P. Arturi, S. Magri, M.P. Girard Bosch, A.S. Arturi \\ Reumatología y Enfermedades Autoinmunes del Hospital Italiano de La Plata. Cátedra Libre de Reumatología de la Universidad Nacional de La \\ Plata. Buenos Aires.
}

\section{Resumen}

En artritis psoriásica (APs), los bloqueantes del factor de necrosis tumoral alfa (anti-TNF) son la opción más adecuada ante la falla a drogas modificadoras. La eficacia y la seguridad de los anti-TNF están ampliamente fundamentadas en la literatura; sin embargo, en algunos casos, pueden presentarse eventos adversos o no se logra la eficacia deseada. Las alternativas terapéuticas en dichos pacientes son acotadas, la inhibición de la interleuquina 6 (IL-6) podría ser una opción. Presentamos dos casos clínicos de pacientes con APs resistentes a anti-TNF que recibieron tocilizumab, en los cuales podemos observar diferencias importantes en el perfil de eficacia de esta droga.

\section{Abstract}

In psoriatic arthritis, the blocking of tumor necrosis factor alpha (antiTNF) is the most suitable option when modifying antirheumatic drugs fail. The efficacy and safety of anti-TNF are largely supported by the literature; however, in some cases, adverse events may occur or the desired efficiency is not achieved. Therapeutic alternatives in these patients are bounded; inhibition of interleukin 6 could be an option. We present two cases of patients with resistant anti-TNF receiving tocilizumab, in which we can observe significant differences in the efficacy profile of the drug.

\section{Introducción}

La APs es una enfermedad inflamatoria crónica que puede comprometer el esqueleto axial y periférico, usualmente seronegativa para el factor reumatoideo y asociada a psoriasis. La prevalencia de psoriasis en la población general se estima entre 2 y $3 \%$, y la presencia de artropatía inflamatoria en estos pacientes varía del 6 al 42\% según las diferentes series ${ }^{1}$. La severidad de la APs no sólo se ve reflejada en el desarrollo de daño articular, sino también en el hecho de que los pacientes que la padecen presentan un incremento en la mortalidad respecto de la población general. Algunos estudios de grandes cohortes de pacientes han demostrado que las causas de muerte son similares a la de la población general, y que el aumento de la mortalidad se asocia a elevada actividad de la enfermedad y a la presencia de compromiso erosivo² ${ }^{2}$ En nuestro país, los datos más recientes informan una incidencia de 6,26 por 100.000 pers/año y una prevalencia de 74 por 100.000 ha- bitantes, las cuales son semejantes a las cifras reportadas en estudios europeos y norteamericanos ${ }^{3}$.

En cuanto al tratamiento de la APs, actualmente en Argentina existen aprobados cinco fármacos biológicos anti-TNF: adalimumab, certolizumab pegol, etanercept, golimumab e infliximab. Estos fármacos son utilizados cuando la terapia con drogas modificadoras tradicionales no logra los objetivos de tratamiento pautados.

Aún no existe en nuestro país una terapia para APs con un mecanismo de acción diferente a los anti-TNF, aunque ya existen fármacos en vía de aprobación como el ustekinumab, para los casos en que estos sean ineficaces o causen eventos adversos. Es habitual, por lo tanto, que dichos pacientes reciban varios cursos de distintos fármacos anti-TNF. El uso de otras terapias biológicas con diferentes mecanismos de acción ha demostrado cierta eficacia en publicaciones, desde el uso fuera de prospecto. Una de ellas es el bloqueo de la IL-6; el tocilizumab es un 
anticuerpo monoclonal humanizado, con actividad contra el receptor de IL-6, se encuentra indicado en pacientes con artritis reumatoidea (AR) y otras enfermedades inflamatorias con excelente eficacia y un aceptable perfil de seguridad. Altos niveles de IL-6 han sido detectados en lesiones de la piel psoriásica y en los tejidos sinoviales de pacientes con $\mathrm{APs}^{4,5}$. Dicha citoquina fue identificada inicialmente como un factor en la diferenciación de células $\mathrm{B}^{6}$, pero en la actualidad se conoce que puede influir también en el desarrollo de células $\mathrm{T}$, incluyendo la diferenciación a Th17, que están implicados en enfermedades autoinmunes, como la $\mathrm{APs}^{4,5}$.

El objetivo de este trabajo es presentar nuestra experiencia con dos casos de APs que han fallado a tres drogas anti-TNF, en los cuales tocilizumab fue indicado fuera de prospecto como alternativa terapéutica.

\section{Caso clínico 1}

Paciente femenina de 45 años de edad con diagnóstico de APs por criterios CASPAR con compromiso periférico poliarticular, erosiva, de 10 años de evolución. Luego de haber recibido combinación de metotrexato $25 \mathrm{mg}$ parenteral semanal con leflunomida $20 \mathrm{mg}$ día por más de un año, se inició terapia biológica con etanercept durante un año, con el cual se evidenció falla secundaria. A continuación recibió infliximab por cuatro meses presentando nuevamente falla secundaria y se optó por adalimumab 40 mg. Este tampoco alcanzó respuesta favorable, observándose a los tres meses de iniciado los siguientes parámetros clinimétricos: DAS28: 5,8, HAQ: 1,2, PASI: 19,2; reactantes de fase aguda ERS: $56 \mathrm{~mm}$ y PCR: $18 \mathrm{mg} / \mathrm{dl}$. Es por ello que se inició tocilizumab a dosis de $8 \mathrm{mg} / \mathrm{kg} / \mathrm{dosis}$ endovenosa cada 4 semanas. A los 6 meses del tratamiento con tocilizumab, la paciente presentaba: DAS28: 6,2, HAQ: 1,2, PASI: 18,2; reactantes de fase aguda ERS: 40 $\mathrm{mm}$, PCR: $12 \mathrm{mg} / \mathrm{dl}$ y evidencia clara de progresión clínica.

\section{Caso clínico 2}

Paciente femenina de 42 años de edad con diagnóstico de APs por criterios CASPAR con compromiso periférico poliarticular, erosiva, de 14 años de evolución. Luego de haber recibido metotrexato $25 \mathrm{mg}$ semanal parenteral por más de tres años, se inicia terapia biológica con infliximab durante un año. Ante la falla secundaria, se rota por etanercept por siete meses y por nueva falla secundaria recibe adalimumab $40 \mathrm{mg}$. Este último con falla primaria y los siguientes parámetros clinimétricos: DAS28: 6,13, HAQ: 2, PASI: 29; reactantes de fase aguda ERS: $80 \mathrm{~mm}$, PCR: 26 $\mathrm{mg} / \mathrm{dl}$. Se decidió iniciar tocilizumab a dosis de $8 \mathrm{mg} / \mathrm{kg} /$ dosis endovenosa cada 4 semanas. Los datos clinimétricos a los 6 meses: DAS28: 3,2, HAQ: 1, PASI: 20; reactantes de fase aguda ERS: $20 \mathrm{~mm}$, PCR: $6 \mathrm{mg} / \mathrm{dl}$ y evidencia de mejoría de la enfermedad.

\section{Discusión}

El aumento de la mortalidad de los pacientes con APs se relaciona con el curso de una enfermedad activa y grave; reflejado por la presencia de enfermedad erosiva y elevación de reactantes de fase aguda al inicio de la enfer$\operatorname{medad}^{2}$. El tratamiento precoz y oportuno con el objetivo de reducir la actividad de la enfermedad ha cobrado un interés especial, por su implicancia en la mejoría del estado funcional, la calidad de vida y la productividad laboral de los pacientes. Además tiene impacto en las comorbilidades que los pacientes con APs presentan: aumento del índice de masa corporal, resistencia a la insulina, diabetes e hipertensión arterial.

Los antiinflamatorios no esteroideos y los corticoides son la terapia utilizada para controlar signos y síntomas de la enfermedad articular, aunque los segundos deben ser utilizados con extrema precaución, no sólo por sus conocidos efectos adversos, sino porque pueden reactivar aún más el compromiso cutáneo. El metotrexato es la droga modificadora elegida para el tratamiento de los síntomas en articulaciones periféricas y piel, pero vale la aclaración que existe mayor grado de evidencia con otras drogas como leflunomida y sulfasalazina, que también son utilizadas ${ }^{7}$.

En los últimos 15 años salieron a la luz un grupo de drogas conocidas como biológicas, así llamadas debido a que su producción se realiza a través de una célula viva, destacándose entre ellas los anticuerpos monoclonales y las proteínas de fusión. Sus mecanismos de acción y moléculas dianas son diversas, las aprobadas para la APs son aquellas dirigidas contra el factor de necrosis tumoral alfa, considerada unas de las citoquinas proinflamatorias por 
excelencia e implicada directamente en la patogenia de la AR y APs. Otro tipo de mecanismo de acción es el dirigido a las células $\mathrm{B}$, más específicamente contra aquellas estirpes que expresan en su superficie el CD 20; la droga más reconocida en este grupo es el rituximab, ampliamente utilizado en enfermedades oncohematológicas, AR y vasculitis ANCA positivas. El abatacept fue desarrollado como un inhibidor de la coestimulación entre la célula presentadora de antígeno y el linfocito T; el mismo bloquea la unión del CD28 con el CD 80/86. Por último, otro blanco importante en referencia a la inhibición de las citoquinas proinflamatorias es la IL-6; el tocilizumab bloquea su receptor soluble y de membrana, y actualmente se encuentran en desarrollo varios fármacos dirigidos a esta diana. Cabe destacar que el ustekinumab es un inhibidor a la subunidad p40 de la IL 12/23 ampliamente utilizado en psoriasis y ha demostrado eficacia en la APs.

Es muy discutido, actualmente, cuáles son las causas por las cuales un paciente falla a este tipo de drogas biológicas, entre ellas se encuentra la formación de anticuerpos anti-fármacos relacionada con la concentración del mismo en sangre y, por otro lado, que en la fisiopatogenia de la enfermedad no está involucrada un solo tipo de citoquina. Se reconocen tres tipos de falla a los fármacos biológicos: la falla primaria se define como ausencia de respuesta a la droga desde el inicio de la terapia, la falla secundaria se produce en aquellos pacientes que han respondido pero al transcurrir el tiempo esta eficacia comienza a perderse, por último se encuentra la falla por toxicidad, la cual no se debe a una cuestión de eficacia sino a la aparición de un evento adverso que por su gravedad obliga a suspender el fármaco.

En este contexto presentamos dos casos clínicos, en los cuales los pacientes han fallado a tres cursos de tratamiento con drogas anti-TNF alfa distintas y nos encontramos en un escenario donde es menester tomar una decisión que se encuentra por fuera de las guías de tratamiento. La búsqueda de un fármaco que pueda reemplazar a los aprobados para determinada patología es una tarea que implica una discusión entre expertos y una búsqueda bibliográfica profunda y responsable.

En nuestra experiencia, tocilizumab presentó una eficacia aceptable sólo en uno de los dos casos expuestos. La revisión bibliográfica demostró la existencia de muy pocos casos de pacientes con APs tratados con inhibidores de la IL-6, los mismos demuestran resultados similares a los presentados en este artículo.

Ogata y cols. publicaron su experiencia en dos casos, en uno de ellos utilizaron la disminución del intervalo de dosis del tocilizumab (cada 2 semanas) como medida de rescate ante la falla. Otra diferencia con nuestros pacientes es que en este caso se utilizó previo al tocilizumab el inhibidor de la subunidad p40 de las IL 12/23 (ustekinumab) ampliamente utilizado para el compromiso cutáneo, y en vías de ser aprobado en nuestro país para el compromiso articular ${ }^{8}$.

Nuestra elección de utilizar un inhibidor de IL-6 se basó en su fundada eficacia en otras artropatías inflamatorias crónicas como la AR. La patogénesis de la APs es desconocida, y se utilizan frecuentemente tratamientos similares a los utilizados para la AR. Debido a que la IL-6 tendría un papel patogénico en la APs, se están llevando a cabo estudios de investigación para probar la eficacia de tocilizumab en APs.

Sin embargo el papel patogénico de IL-6 en la AR y APs es diferente. La razón exacta de la diferencia en la eficacia de tocilizumab en la AR y APs es poco clara. Se ha descripto recientemente a través de estudios de imágenes, histológicos y genéticos que la inflamación del órgano entésico ocurre en etapas muy tempranas de la APs y en forma subclínica, este daño implica un proceso de reparación en zonas cercanas a articulaciones, configurando un proceso autoinflamatorio y no autoinmune.

Por lo tanto, una hipótesis posible es que pueden existir diferentes roles patogénicos de IL-6 en dichas patologías. Basándose en las observaciones de la dependencia de citoquinas en los modelos de artritis, la artritis inducida por colágeno tipo II requiere tanto la IL-6 y TNF, mientras que la artritis inducida por anticuerpos contra el colágeno de tipo II requiere sólo TNF. Esto sugiere que la IL-6 es necesaria para la producción de anticuerpos específicos para componentes de la articulación (fase autoinmune) y el TNF es necesario para la generación de la artritis (fase de inflamación) $)^{9,10}$. En la AR, el TNF contribuye principalmente a la fase efectora de la artritis y la IL-6 contribuye a la fase de cebado de la artritis. En la APs, la fase efectora relacionada con el TNF es similar a la de en la AR, pero la fase de cebado relacionada con IL-6 podría ser diferente ${ }^{9}$. Tocilizumab entonces podría inhibir sólo marcadores inflamatorios, no de artritis directamente. Los efectos en 
la mejoría de la artritis con tocilizumab dependerán, por lo tanto, de la modulación inmune en lugar de la supresión inflamatoria ${ }^{11}$. En relación con esta teoría, nosotros observamos una mejor respuesta en la paciente 2, quien presentaba parámetros de inflamación más elevados.

Las presentes observaciones son limitadas por el pequeño número de pacientes, estudios clínicos mayores son necesarios para comprobar la eficacia de tocilizumab en APs, aunque en la actualidad otros mecanismos de acción muy promisorios se encuentran en vías de aprobación para la APs como son ustekinumab y apremilast.

\section{Bibliografía}

1. Gladman DD, Shuckett ML, Russell JC, et al. Psoriatic Arthritis (PSA) - An analysis of 220 patients. Quarterly Journal of Medicine 1987; 62:127-41.

2. Gladman DD, Farewell VT, Wong K, Husted J. Mortality studies in psoriatic arthritis: results from a single outpatient center. II. Prognostic indicators for death. Arthritis Rheum 1998; 41(6):1103-10.

3. Soriano ER, Rosa J, Velozo E, Schpilberg M, Imamura PM, et al. Incidence and prevalence of psoriatic arthritis in Buenos Aires, Argentina: a 6-year health management organization-based study. Rheumatology 2011; 50 (4):729-34.

4. Atzeni F, Ventura D, Batticciotto A, Boccassini L, Sarzi-Puttini P. Interleukin 6 blockade: tocilizumab in psoriatic arthritis. J Rheumatol 2012; 89:97-9.
5. Kuijk V, Tak PP. Synovitis in psoriatic arthritis: immunohistochemistry, comparisons with rheumatoid arthritis, and effects of therapy. Curr Rheumatol Rep 2011; 13:353-9.

6. Wendling D, Letho-Gyselinck H, Guillot X et al. Psoriasis onset with tocilizumab treatment for rheumatoid arthritis. J Rheumatol 2012; 39:657.

7. Soriano ER, Rosa J. Update on the treatment of peripheral arthritis in psoriatic arthritis. Curr Rheumatol Rep 2009; 11:270-7.

8. Ogata A, Umegaki N, Katayama I, Kumanogoh A, Tanaka T. Psoriatic arthritis in two patients with an inadequate response to treatment with tocilizumab. Joint Bone Spine 2012; 79:85-7.

9. Kagari T, Doi H, Shimozato T. The importance of IL-1 beta and TNF-alpha, and the non-involvement of IL-6, in the development of monoclonal antibody-induced arthritis. J Immunol 2002; 169:1459-66.

10. Iwakura Y, Nakae S, Saijo S, et al. The roles of IL$17 \mathrm{~A}$ in inflammatory immune responses and host defence against pathogens. Immunol Rev 2008; 226:57-79.

11. Ogata A, Kumanogoh A, Tanaka T. Pathological role of interleukin-6 in psoriatic arthritis. Arthritis 2012; 2012:1-6. 